\title{
Dermoscopy of nevus comedonicus
}

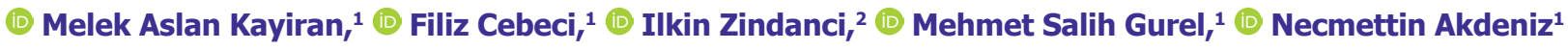 \\ ${ }^{1}$ Department of Dermatology, Istanbul Medeniyet University Goztepe Training and Research Hospital, Istanbul, Turkey \\ ${ }^{2}$ Department of Dermatology, Health Sciences University Umraniye Training and Research Hospital, Istanbul, Turkey
}

Cite this article as: Aslan Kayiran M, Cebeci F, Zindanci I, Gurel MS, Akdeniz N. Dermoscopy of nevus comedonicus. North Clin Istanb 2019;6(4):401-402.

A 38-year-old male patient admitted to our clinic due to a lesion on the left side of his body. The asymptomatic lesion was present in the patient since his childhood. The dilated follicular openings were spreading linearly from the left areola to his back, and some of them had black keratotic plugs reminiscent of open comedones (Fig. 1A-B). No evidence of any additional skin disease was observed. Multiple, circular and oval-shaped, white-light brown colored homogenous areas along with some dark grey-blackish keratin plugs were seen on its dermoscopic examination (Fig. 2A-B). We used an epiluminescence microscopy (Dermlite DL4W, Leofarma, CA, USA) without immersion oil. There were no systematic findings. The patient did not want to have any treatment because it was only a cosmeceutical situation. However, the patient was followed up because the disease might have been accompanied by some systemic anomalies. This case is presented for emphasizing the point that dermoscopy can be supportive of the diagnosis of nevus comedonicus and for contributing to the relevant literature with its dermoscopic findings.

Nevus comedonicus is a rare type of nevus that arises from the epithelial part of the center of the pilosebase unit. It is characterized by the combination of the dilated follicular openings resembling comedones. Nevus comedonicus may be seen in any part of the body but especially on face and neck. It is usually solitary, but sometimes, it may be associated with central nervous system (microcephaly, mental deficiency, pathologic electroencephalographic findings, dysgenesis of corpus callosum), skeletal system (syndactyly, clinodactyly, polydactyly, scoliosis, vertebral defects) and eye (ipsilateral cataract, corneal erosions) anomalies, and in that case, it is called nevus comedonicus syndrome. Ac-
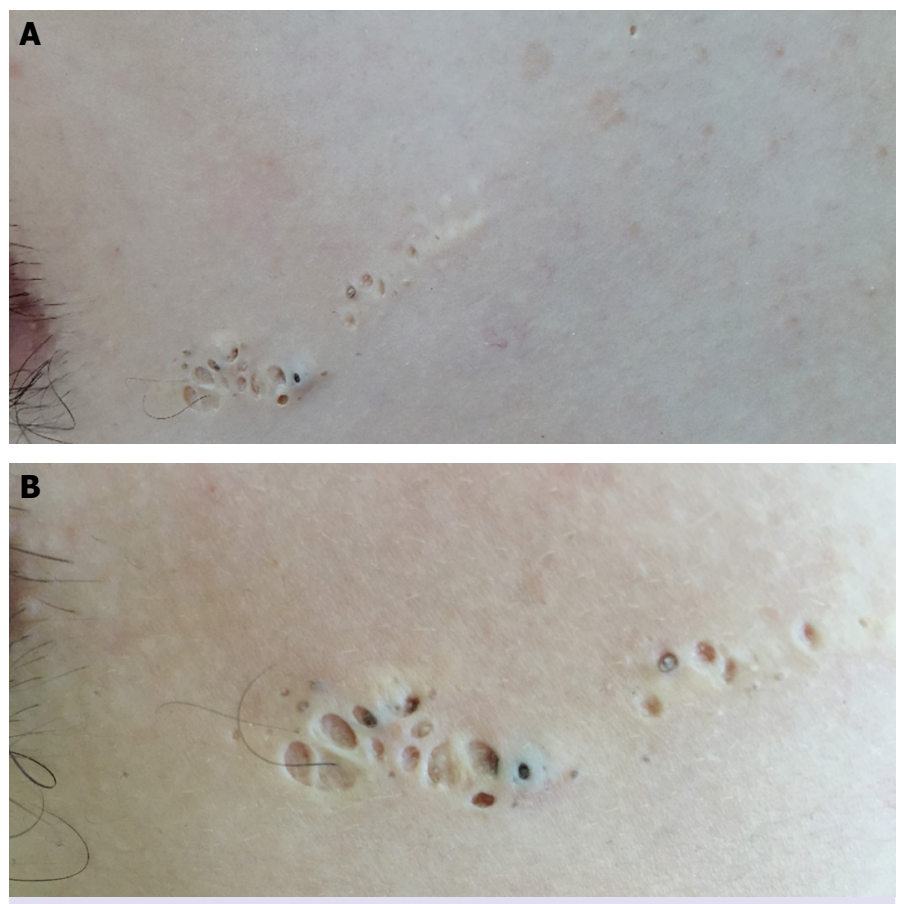

FIGURE 1. (A, B) The dilated follicular openings are spreading linearly from the left areola to his back, and some of them have black keratotic plugs reminiscent of open comedones.

Received: January 02, 2018 Accepted: November 01, 2018 Online: November 28, 2018

Correspondence: Dr. Melek ASLAN KAYIRAN. Istanbul Medeniyet Universitesi Goztepe Egitim ve Arastirma Hastanesi, Deri ve Zuhrevi Hastaliklar Anabilim Dali, Istanbul, Turkey. 
companying skin diseases are ichthyosis, trichilemmal cysts, sebaceous nevi, Becker nevus, leukoderma, white hair, Sturge Weber Syndrome and hemangiomas. The treatment options, if needed, are topical retinoid applications, and in resistant forms, laser therapy or surgical excision. History and clinical examination bring about the diagnosis, and there is no need to carry out a histopathological examination in most cases. The diagnosis can be supported by dermoscopic findings. We found many circular and oval-shaped, white and light brown colored homogenous areas along with some dark grey-blackish keratin plugs on the dermoscopic examination. When we review the relevant literature, to our knowledge, there are only two studies regarding the dermoscopy of the cases, which remained underresearched. The dermoscopy of our case was consistent with the findings of the previous two studies.

The dermoscopic findings of the previous cases are multiple, well-defined, structureless brown homogenous areas surrounding the keratin plugs and many circular homogenous areas in light and dark-brown shades with remarkable keratin plugs. Dermoscopy may help to differentiate nevus comedonicus from comedones of acne. There are many homogenous, usually circular, dark brown and black areas and those are located superficially on dermoscopic examination of comedones

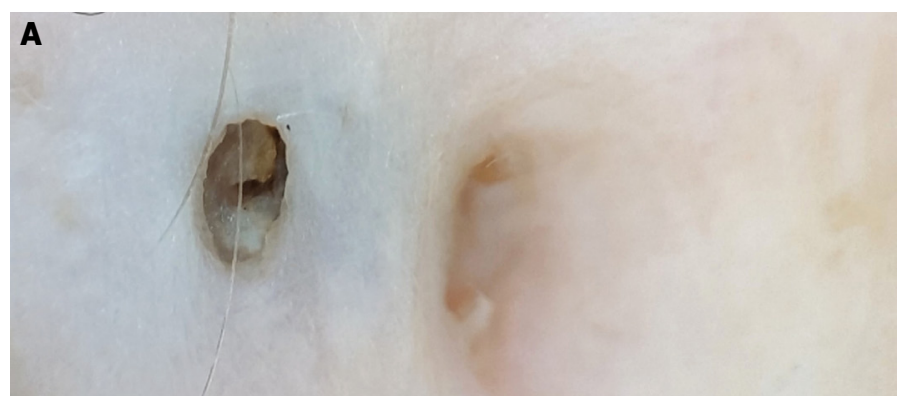

B

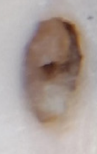

FIGURE 2. (A, B) Multiple circular and oval-shaped, whitelight brown colored homogenous areas along with some dark grey-blackish keratin plugs are seen.

of acne vulgaris. Nevus sebaceous, a type of epidermal nevus, may be considered for differential diagnosis. Bright and yellow dots which are not associated with hair follicles and sometimes yellow globules with crown vessels are seen on dermoscopy of sebaceous nevus. 